\title{
Future perspectives on rare pulmonary diseases and rare presentations of common disorders
}

\author{
Sergio Harari ${ }^{1}$, Marc Humbert ${ }^{2}$ and Vincent Cottin ${ }^{3,4}$
}

\begin{abstract}
Affiliations: ${ }^{1}$ Unità Operativa di Pneumologia e Terapia Semi-Intensiva Respiratoria - Servizio di Fisiopatologia Respiratoria ed Emodinamica Polmonare-Ospedale San Giuseppe MultiMedica, Milan, Italy. ${ }^{2}$ Centre National de Référence de l'Hypertension Pulmonaire Sévère, Hôpital Bicêtre, Hôpitaux Universitaires Paris-Sud, Assistance Publique Hôpitaux de Paris, Le Kremlin-Bicêtre, and ${ }^{3}$ Hospices Civils de Lyon, Hôpital Louis Pradel, Service de pneumologie - Centre de référence national des maladies pulmonaires rares et Centre de compétences de l'hypertension artérielle pulmonaire, Lyon, and "Université de Lyon, Université Claude Bernard Lyon 1, INRA, UMR754 INRA-Vetagrosup EPHE IFR 128, Lyon, France.
\end{abstract}

Correspondence: S. Harari, Unità Operativa di Pneumologia e Terapia Semi-Intensiva Respiratoria - Servizio di Fisiopatologia Respiratoria ed Emodinamica Polmonare-Ospedale San Giuseppe MultiMedica, Via San Vittore 12, 20123 Milan, Italy. E-mail: sharariahotmail.it

0

@ERSpublications

Opening up opportunities for rare diseases allows exploration of pathogenic mechanisms in development of rare diseases http://ow.ly/mRj5u

The International Congress on Pulmonary Rare Diseases and Orphan Drugs is a unique European event which, since 2005, has been held every 2 years in Milan, Italy. The 5th Congress was held in February 2013 (www.pulmonaryrarediseases.com) with the next Congress being held on February 27-28, 2015, in conjunction with World Rare Diseases Day and during the year of the Universal Exposition 2015, which will also take place in Milan. Over the years, the Congress has increasingly expanded; it has grown in importance and has become an important European, as well as international, event. Nowadays, this event is a wellknown and eagerly awaited rendezvous, and has become a valuable asset for the entire international scientific community in the field of rare (orphan) pulmonary diseases.

The success of this Congress is based on its many profiles, international, translational and clinical, which gather together scientists from different fields of expertise (from pulmonary hypertension ( $\mathrm{PH}$ ) to lymphangioleiomyomatosis (LAM)) providing them with a valuable opportunity to encompass a broad range of insights within the area of respiratory medicine. Although most topics relate to rare pulmonary diseases, representing the core of the Congress, this year several rare presentations of common respiratory diseases were covered in the programme, including the management of severe asthma and hypereosinophilic asthma. Topics for the programme were suggested by an international scientific committee comprised of outstanding European and US physicians. For example, the 2013 committee comprised E.H. Bel, V. Cottin, M. Humbert, M. Matucci-Cerinic, J. Moss, G. Simonneau, C. Vancheri, A. Vonk-Noordegraaf and S. Harari (Congress Chair). The Congress fosters interactions between specialties and subspecialties, ranging from severe asthma to pulmonary fibrosis, rare presentations of cancer, connective tissue diseases and $\mathrm{PH}$. Thus, in addition to pulmonologists, other clinical specialists were involved as speakers and attendees, especially rheumatologists, as well as cardiologists, internal medicine specialists, immunologists, dermatologists and many others.

Received: June 182013 | Accepted: June 212013

Conflict of interest: Disclosures can be found alongside the online version of this article at err.ersjournals.com

Provenance: Publication of this peer-reviewed article was supported by the World Scleroderma Foundation, Switzerland (principal sponsor, European Respiratory Review issue 129).

Copyright @ERS 2013 
TABLE 1 Papers published on rare pulmonary diseases in European Respiratory Society publications from 1990 to June 2013

1990-1999

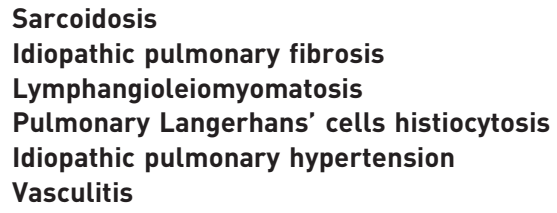

2000-2009

2010-2013

Opening up new prospects and opportunities for rare diseases, by gathering different medical specialties and involving both researchers and physicians, allows scientists to explore some common pathogenic mechanisms in the development of rare diseases. Moreover, by integrating different sources of scientific knowledge, innovative therapeutic approaches may also be tested. The translational approach has recently been reinforced by moving from basic research to clinical investigation.

The proceedings of the Congresses have been published previously in international journals [1,2]. Selected papers from the 2011 Congress have been published previously in the European Respiratory Review (ERR) [3]. This year, it is a privilege that the proceedings of the 2013 International Congress on Pulmonary Rare Diseases and Orphan Drugs will be published more extensively in the current issue of the ERR. The increasing scientific interest for rare pulmonary diseases throughout the entire European medical community is witnessed by the continuous rise in the number of scientific publications related to these topics [3], and the growing attention paid to this field by the publications of the European Respiratory Society (table 1).

The proceedings are developed according to this philosophy, i.e. facing a wide range of problems and diseases, and always bearing in mind possible common features and links between different conditions. Thus, the article by WENER and BEL [4] informs us how we can learn to distinguish between "difficult-tocontrol" and "severe refractory" asthma, as well as how to practically manage these difficult situations. The review by GARCIA et al. [5] illustrates the possible role of anti-interleukin-5 compounds in the treatment of severe eosinophilic asthmatic patients with a history of frequent exacerbations. MONTANI et al. [6] extensively review the issue of drug-induced pulmonary arterial hypertension (PAH); a story which resembles that of the Arab Phoenix rising from its ashes. In addition, the authors discuss the most commonly involved drugs, including aminorex fumarate (which was used in the late 1960s), fenfluramine (which was used in the 1980s) and the most recently used, benfluorex. Novel therapies and possible future approaches to PAH are discussed by SEFERIAN and SIMONNEAU [7], experts from one of the most important European centres dedicated to the research and treatment of pulmonary vascular diseases. DeLCROIX [8] discusses the rationale for the use of PAH-targeted drugs in chronic thromboembolic pulmonary hypertension, which, until now, was essentially a surgical disease. The highly clinically relevant issue of $\mathrm{PH}$ in interstitial lung diseases (ILD) (ranging from sarcoidosis, idiopathic pulmonary fibrosis (IPF), multiple cystic lung diseases including LAM, to pulmonary Langerhans' cell histiocytosis) is reviewed by CAMINATI et al. [9], including prevalence, mechanisms of disease and possible future therapies. The vast area of ILD is covered by a number of authors, including COTTIN [10], who offers an exhaustive and modern view on the significance of connective tissue disease features in patients with pulmonary fibrosis. VANCHERI [11] discusses the possible links between IPF and lung cancer (a very hot and intriguing topic), and CAPPELLI et al. [12] discuss the role of immunosuppressive therapy for ILD in the setting of systemic sclerosis. ANTONIOU et al. [13] review the role of pharmacological treatment in IPF, by looking at future issues and new interesting ongoing studies, and discuss the critical issue of end-points in clinical trials. Finally, SHIM et al. [14] explore the experimental and animal data regarding a very particular, relevant and not wellknown problem: the effect of oestrogen in sex-specific lung diseases, especially LAM.

We hope you will enjoy these reviews which provide an interesting adventure through the transversal and fascinating world of research and clinical approach in medicine.

\section{References}

Harari S, Agostini C. New frontiers for rare pulmonary diseases. Sarcoidosis Vasc Diffuse Lung Dis 2005; 22: Suppl. $1, \mathrm{~S} 1-\mathrm{S} 3$.

Harari S, Agostini C. Rare pulmonary diseases: a path to the future. Respir Med 2010; 104: Suppl. 1, S1.

Harari S, Cottin V, Humbert M. Global effort against rare and orphan diseases. Eur Respir Rev 2012; 21: 171-172.

Wener RRL, Bel EH. Severe refractory asthma: an update. Eur Respir Rev 2013; 22: 227-235. 
5 Garcia G, Taillé C, Laveneziana P, et al. Anti-interleukin-5 therapy in severe asthma. Eur Respir Rev 2013; 22: 251-257.

6 Montani D, Seferian A, Savale L, et al. Drug-induced pulmonary arterial hypertension: a recent outbreak. Eur Respir Rev 2013; 22: 244-250.

7 Seferian A, Simonneau G. Therapies for pulmonary arterial hypertension: where are we today, where do we go tomorrow. Eur Respir Rev 2013; 22: 217-226.

8 Delcroix M. Chronic post-embolic pulmonary hypertension: a new target for medical therapies? Eur Respir Rev 2013; 22: 258-264.

9 Caminati A, Cassandro R, Harari S. Pulmonary hypertension in chronic interstitial lung diseases. Eur Respir Rev 2013; 22: 292-301.

10 Cottin V. Significance of connective tissue diseases features in pulmonary fibrosis. Eur Respir Rev 2013; 22: 273-280.

11 Vancheri C. Common pathways in idiopathic pulmonary fibrosis and cancer. Eur Respir Rev 2013; 22 : $265-272$.

12 Cappelli S, Guiducci S, Bellando Randone S, et al. Immunosuppression for interstitial lung disease in systemic sclerosis. Eur Respir Rev 2013; 22: 236-243.

13 Antoniou KM, Margaritopoulos GA, Siafakas NM. Pharmacological treatment of idiopathic pulmonary fibrosis: from the past to the future. Eur Respir Rev 2013; 22: 281-291.

14 Shim B, Pacheco-Rodriguez G, Kato J, et al. Sex-specific lung diseases: effect of oestrogen on cultured cells and in animal models. Eur Respir Rev 2013; 22: 302-311. 